\title{
Identification of potential probiotic Lactobacillus plantarum isolates with broad-spectrum antibacterial activity
}

\author{
Changkun Li • Yongfu Chen • Lai-Yu Kwok • \\ Xia Chen • Haijing Yu • Huijuan Yang • Jie Yang • \\ Jiangang Xue • Tiansong Sun • Heping Zhang
}

Received: 13 August 2014 /Revised: 15 November 2014 / Accepted: 17 November 2014 /

Published online: 10 December 2014

(C) INRA and Springer-Verlag France 2014

\begin{abstract}
Food deterioration is largely related to contamination by undesirable microorganisms; it can cause economical loss and serious health-related problems. Owing to increased awareness of health issues by consumers, biological food preservation using antibacterial Lactobacillus species is being increasingly studied. Here, we make a preliminarily assessment of the antibacterial activity of 347 Lactobacillus plantarum isolates against five common food-borne pathogens (Escherichia coli, Staphylococcus aureus, Listeria monocytogenes, Salmonella typhimurium, and Shigella flexneri). Nine of these isolates had broad-spectrum antibacterial activity and were selected for further experimentation. Subsequent assays based on physical, chemical, and sensory evaluations of yoghurts fermented in the presence or absence of each of the selected isolates and persistence of antibacterial activity following protease challenge revealed that L. plantarum isolate IMAU10216 was superior to the other isolates. L. plantarum IMAU10216 also exhibited high in vitro gastrointestinal tract tolerance. To conclude, we have identified a novel bioactive antibacterial L. plantarum isolate with potential for use as a probiotic in the production of fermented milk or other related dairy products. Further in vivo studies are now required.
\end{abstract}

Keywords Lactobacillus plantarum $\cdot$ Food pathogen $\cdot$ Screening $\cdot$ Antibacterial activity

Electronic supplementary material The online version of this article (doi:10.1007/s13594-014-0206-1) contains supplementary material, which is available to authorized users.

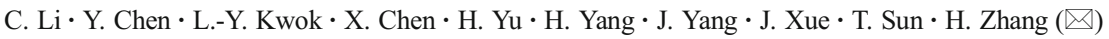

Key Laboratory of Dairy Biotechnology and Engineering, Ministry of Education, Inner Mongolia

Agricultural University, Huhhot 010018, People's Republic of China

e-mail: hepingdd@vip.sina.com

Y. Chen $\cdot$ H. Zhang

Synergetic Innovation Center of Food Safety and Nutrition, Jiangnan University, Wuxi 214000, People's

Republic of China 


\section{Introduction}

Food quality and safety is an emerging public health concern, as deterioration of food may cause both great economical loss and serious health-related problems (Hussain and Dawson 2013). Food deterioration is usually due to contamination by spoilage or pathogenic microbes that are ubiquitous in raw food or the immediate environment. In addition, the use of chemical preservatives in food production has been significantly reduced recently, due to increased public awareness of the health concerns associated with them. The addition of natural biopreservatives, such as isolates of lactic acid bacteria (LAB) with antibacterial activity, is one potential strategy to both improve food quality and extend shelf life (Smaoui et al. 2010). However, the practical application of such an approach does suffer from technical problems such as incompatibility with the taste of food and loss of antimicrobial activity during food digestion (Gálvez et al. 2007).

Lactobacillus plantarum is a versatile and widely distributed LAB; it has greater potential as a probiotic biopreservative than many other Lactobacillus species because of its dual role as an indigenous human gut inhabitant and its long history of safe use as a starter culture in food fermentation (De Vries et al. 2006). Some L. plantarum isolates have been reported to exert beneficial health effects following consumption, including maintenance of the colonic microbial balance, elimination of potential food toxicants, protection from intestinal infections, reduction of inflammation, and lowering of blood cholesterol (Nguyen et al. 2007). Furthermore, some L. plantarum isolates have good antimicrobial characteristics; both Hernández et al. (2005) and Smaoui et al. (2010) successfully isolated antimicrobial L. plantarum from food sources through large-scale screening experiments. These two reports suggest that large-scale screening is a feasible approach to identify and isolate LAB with antibacterial activity. Further studies demonstrated the suitability of these isolates in food production and subsequent desirable antimicrobial activity after food processing (Cleveland et al. 2001).

The primary objective of the current study was to screen $347 \mathrm{~L}$. plantarum isolates originating from food, for potential isolates with broad-spectrum antibacterial activity. We also evaluated the antibacterial activity of a subset of the most promising isolates in combination with yoghurt starters and quantified their physiochemical and sensory properties and persistence of antibacterial activity in simulated, in vitro, gastrointestinal environments.

\section{Materials and methods}

\subsection{Bacterial isolates and reagents}

Three hundred and forty-seven isolates of L. plantarum were obtained from the Lactic Acid Bacteria Culture Collection (LABCC) of the Key Laboratory of Dairy Biotechnology and Engineering, Inner Mongolia Agricultural University, Inner Mongolia, People's Republic of China. These isolates were all from food and identified as L. plantarum using a combination of traditional physiological and biochemical identification methods and 16S ribosomal RNA (rRNA) gene sequence analysis; their 16S rRNA gene sequences were submitted to GenBank (NCBI) (Zhang et al. 2012). All 
isolates were stored long-term in a skimmed milk medium (SMM, NZMP LTD., Zealand) at $-80{ }^{\circ} \mathrm{C}$ and then grown in de Man, Rogosa, and Sharpe (MRS, Oxoid Ltd., England) broth at $37{ }^{\circ} \mathrm{C}$ for $24 \mathrm{~h}$, following standard methods (Vinderola et al. 2002) prior to use in experiments. For use as a culture medium in experiments, whole milk powder was purchased from NZMP LTD (Wellington, New Zealand) and contained $39.1 \mathrm{~g} / 100 \mathrm{~g}$ of lactose, $26.8 \mathrm{~g} / 100 \mathrm{~g}$ of fat, and $25.0 \mathrm{~g} / 100 \mathrm{~g}$ of protein.

Antimicrobial activity of $L$. plantarum isolates was evaluated against five indicator bacterial species that are all food-borne pathogens: Escherichia coli (isolate O157:H7), Staphylococcus aureus (isolate ATCC12600), L. monocytogenes (isolate ATCC15313), Salmonella typhimurium (isolate ATCC13311), and Shigella flexneri (isolate CMCC51592). All isolates of indicator species were obtained from the American Type Culture Collection (ATCC, Manassas, Virginia, USA) or the National Medical Centre Culture Collection (CMCC, Beijing, Chain). The first three indicator species were cultured in Luria-Bertani medium (LB), tryptic soy broth (TSB), and brain heart infusion (BHI), respectively, while Salmonella typhimurium and Shigella flexneri were cultured in nutrient broth (NB) following standard methods (Hernández et al. 2005). All media were purchased from Oxoid Ltd. (England). All indicator species were grown at $37{ }^{\circ} \mathrm{C}$ in their corresponding culture media, subcultured three times at $24-\mathrm{h}$ intervals, and then maintained at $4{ }^{\circ} \mathrm{C}$ for short-term storage prior to use in experiments.

\subsection{Large-scale screening of 347 L. plantarum isolates for inhibitory activity} against five indicator bacterial species

For each of the 347 isolates of L. plantarum, spores from the 24-h culture in MRS were resuspended in phosphate buffer, after centrifugation and washing, to achieve a concentration of $1 \times 10^{9}$ CFU.mL $\mathrm{mL}^{-1} ; 2 \mathrm{ml}$ of this suspension was inoculated into $100 \mathrm{~g}$ of whole milk $(12 \%$ whole milk powder in $88 \%$ distilled water that had been pasteurized and was therefore sterile) and incubated at $37{ }^{\circ} \mathrm{C}$ for $24 \mathrm{~h}$ to allow fermentation to proceed. There were three replicates for each isolate of $L$. plantarum. The resulting cultures were centrifuged at $4,000 \times g$ for $10 \mathrm{~min}$ and the supernatants collected. Each supernatant was filtered through a sterile $0.22-\mu \mathrm{m}$ pore size membrane and stored at $-20{ }^{\circ} \mathrm{C}$ prior to testing for antibacterial activity in a well diffusion assay (see Sect. 2.2.1).

\subsubsection{Well diffusion assay}

We followed the methods of Vinderola et al. (2002). Briefly, each indicator bacterium was cultured as described in Sect. 2.1 to provide suspensions with a concentration of $1 \times 10^{6}$ CFU.mL ${ }^{-1}$. Suspensions of indicator bacteria were mixed with molten MRS agar $(1.5 \%, w / v)$ that had been cooled to $50{ }^{\circ} \mathrm{C}$ and then poured into sterile 9-cm-diameter Petri dishes; each dish contained $25 \mathrm{ml}$ of agar, and the concentration of indicator bacteria was approximately $1 \times$ $10^{6}$ CFU.mL ${ }^{-1}$. After the agar had solidified, 8.00-mm diameter plugs were excised from the center of each plate using a sterile cork borer. Culture supernatants from all samples of each $L$. plantarum isolate to be tested $(100 \mu \mathrm{L})$ were transferred into the holes left by the excised plug and allowed to diffuse into the agar for $12 \mathrm{~h}$ at $4{ }^{\circ} \mathrm{C}$ before aerobic incubation for $48 \mathrm{~h}$ at 
$37{ }^{\circ} \mathrm{C}$. The diameter of the growth-free inhibition zone around each hole was then measured with an electronic vernier caliper.

2.3 Determining the antibacterial activity of selected L. plantarum isolates when coinoculated with a commercial yoghurt starter and then challenged with the gastrointestinal proteases pepsin and trypsin

Based on the initial screen of antibacterial activity, nine isolates were selected for further evaluation in combination with a standard yoghurt starter. Selected isolates were the ones that had the greatest antibacterial activity against the largest number of indicator bacteria. For each selected isolate, $2 \mathrm{~mL}$ of a $1 \times 10^{9} \mathrm{CFU}_{\mathrm{mL}}^{-1}$ suspension in phosphate buffer was inoculated into $100 \mathrm{~g}$ of whole milk as described in Sect. 2.2. To this, $0.003 \mathrm{~g}$ of a commercial yoghurt starter (YC-X11 = Lactobacillus delbrueckiil Streptococcus thermophilus $=1: 1$ from Chr. Hansen Co., Ltd, Denmark) was added and the resulting mixture incubated at $42{ }^{\circ} \mathrm{C}$ for $6 \mathrm{~h}$ to allow fermentation to proceed. A control with only the commercial yoghurt starter was prepared in parallel, and there were three replicates for each isolate. Following fermentation, the resulting cultures were centrifuged at $4,000 \times g$ for $10 \mathrm{~min}$; the supernatants were collected, filtered, and stored as described in Sect. 2.2 prior to challenge with the proteases pepsin and trypsin simulating the gastrointestinal environment (see Sect. 2.3.1) and subsequent evaluation of antibacterial activity using the well diffusion assay (see Sect. 2.2.1).

\subsubsection{Protease challenge}

The $\mathrm{pH}$ of the fermented milk supernatants $(2 \mathrm{~mL})$ was adjusted to 2.5 with concentrated hydrochloric acid before adding $3 \mathrm{mg}$ of pepsin (Sigma-Aldrich, St. Louis, MO, USA). The culture was incubated at $37^{\circ} \mathrm{C}$ in a water bath for $2 \mathrm{~h}$. Then, the $\mathrm{pH}$ of the resultant mixture was adjusted to 8.0 with $0.5 \mathrm{~mol} . \mathrm{L}^{-1}$ sodium hydroxide, before adding $1 \mathrm{mg}$ of trypsin (Sigma-Aldrich, St. Louis, MO, USA) and incubating at $37^{\circ} \mathrm{C}$ for a further $2 \mathrm{~h}$. The $\mathrm{pH}$ was then readjusted to its original value, and its antibacterial activity was assessed using the well diffusion assay (see Sect. 2.2.1). Controls for each isolate that were not challenged with proteases were prepared in parallel, and there were three replicates for each isolate and treatment.

2.4 Physical, chemical, and sensory properties of milk fermented with selected L. plantarum isolates

Fermented milk was produced as described in Sect. 2.3 with the commercial yoghurt starter alone or with each of the selected L. plantarum isolates. Because the fermented milk was to be evaluated for taste, all reagents used were of food grade, and operations complied with the requirements of Chinese laws and regulations.

Four physical and chemical properties of fermented milk were measured: $\mathrm{pH}$, titratable acidity (TA), free amino nitrogen (FAN), and viscosity. The $\mathrm{pH}$ was measured using a pHSJ-3F pH meter (Leici, Shanghai, China). TA was determined by titration with $\mathrm{NaOH}$ using phenolphthalein as the indicator (National Standards of the People's Republic of China 1996). The quantity of FAN was estimated using the ortho-phthalaldehyde (OPA) method of 
Church et al. (1983), and the viscosity was measured using a viscometer (DVE, Brookfield, USA).

The remaining fermented milk was stored at $4{ }^{\circ} \mathrm{C}$ for $24 \mathrm{~h}$ before sensory evaluation. Sensory evaluations were made by students $(n=30)$ from the food science discipline, and they were all trained in sensory evaluation using the methods of Obi et al. (2010). The mouth of the tester was rinsed with water before samples were tested and between different samples. The criteria evaluated were appearance, odor, flavor, and texture. Each criterion was scored from 1 (obnoxious) to 9 (highly desirable), and an overall mean score was calculated for each sample by averaging the scores for each assessment criterion.

\subsection{Tolerance of selected L. plantarum isolates to artificial gastrointestinal juices}

Tolerance of the selected L. plantarum isolates to artificial gastrointestinal juices was evaluated following the methods of Usman and Hosono (1999). Briefly, L. plantarum isolates were grown in MRS at $37^{\circ} \mathrm{C}$ overnight. Cells were collected by centrifugation and were washed twice with PBS before resuspending in the same buffer. To $0.5 \mathrm{~mL}$ of bacterial suspension, $4.5 \mathrm{~mL}$ of simulated gastric juice was inoculated (content $0.3 \%$ pepsin, Sigma-Aldrich, St. Louis, MO, USA, pH 2.5). An aliquot of $0.5 \mathrm{~mL} \mathrm{3-h}$ incubated gastric juice-bacterial mixture was further inoculated into $4.5 \mathrm{~mL}$ simulated intestinal juice (content $0.1 \%$ trypsin and $0.3 \%$ bile, Sigma-Aldrich, St. Louis, MO, USA, $\mathrm{pH}$ 8.0) and incubated at $37{ }^{\circ} \mathrm{C}$ anaerobically. Gastric transit tolerance was calculated from the total viable counts in the gastric juice-bacterial mixture after 0 and $3 \mathrm{~h}$ of incubation and the total viable counts after 4 and $8 \mathrm{~h}$ of incubation in simulated intestinal juice.

The survival rate was calculated according to the following equation:

$$
\text { Survival rate }(\%)=\log N_{1} / \log N_{0} \times 100 \%
$$

where $N_{0}$ and $N_{1}$ represented the total viable counts of $L$. plantarum before and after the respective treatment, respectively. There were three replicates of each isolate and control.

\subsection{Tolerance of selected L. plantarum isolates to bile}

Tolerance of the selected L. plantarum isolates to bile was evaluated following the methods of Walker and Gilliland (1993). Briefly, MRS-THIO broth (MRS supplemented with $0.2 \% w / v$ sodium thioglycollate) (Kanto, Japan) supplemented with $0.3 \%(w / v)$ oxgall (dehydrated fresh bile, DIFCO, Canada) was freshly prepared and was inoculated in a $1 \%$ proportion $(v / v)$ to suspensions of each of the selected L. plantarum isolates that had been incubated overnight as described previously. Control samples without oxgall were prepared in parallel, and there were three replicates of each isolate. The mixtures were incubated at $37{ }^{\circ} \mathrm{C}$ in a water bath. Absorbance at $620 \mathrm{~nm}$ was measured using a spectrophotometer (U-1700, Shimadzu Corporation, Japan) against the corresponding non-inoculated blank samples. Growth was followed until a 0.3-unit difference in absorbance was reached. The delay in growth with time (h) in oxgall-containing culture medium was considered as the lag time. 


\subsection{Statistical analysis}

Each assay was repeated on three occasions to ensure reproducibility of the results. All data are presented as means \pm standard deviation. Significant differences between groups were evaluated by analysis of variance (ANOVA) using the software package SPSS (version 16). $P<0.05$ was considered as statistically significant.

\section{Results and discussion}

\subsection{Initial screening for antibacterial activity}

Antibacterial activity of 347 food-derived isolates of L. plantarum isolates against five indicator bacteria that were all food-borne pathogens was determined. The highest antibacterial activity (inhibition zones of $>12.00 \mathrm{~mm}$ ) was achieved by $6.6,3.5,4.3$, 3.2 , and $2.6 \%$ of L. plantarum isolates against E. coli, Salmonella typhimurium, Shigella flexneri, Staphylococcus aureus, and L. monocytogenes, respectively. This is in line with the study of Smaoui et al. (2010) who found that only one isolate of L. plantarum (TN635) out of 54 isolates evaluated showed significant levels of inhibitory activities against four Gram-negative pathogenic bacteria (Salmonella enterica, Pseudomonas aeruginosa, Hafnia sp., and Serratia sp.).

Based on these results, nine isolates could be identified as having broad and effective antibacterial activity against four (IMAU70095 and IMAU50045) or all five of the indicator bacteria (IMAU80106, IMAU10996, IMAU10216, IMAU70023, IMAU30043, IMAU30162, and IMAU10256) (Supplementary Table 1). These nine isolates were selected for further experimentation. The production of antibacterial compounds such as organic acids, short-chain fatty acids, and bacteriocins is a desirable characteristic of probiotics. The broad-spectrum antibacterial activity against both Gram-positive and Gram-negative bacteria observed in the nine selected isolates was similar to the results of Kaktcham et al. (2012).

3.2 Antibacterial activity of selected $L$. plantarum isolates when coinoculated with a commercial yoghurt starter

It is known that there can be variation in in situ antibacterial activity of LAB when combinations of isolates are used in food applications (Gálvez et al. 2007). For this reason, we evaluated the antibacterial activity of the selected isolates in the context of yoghurt production when they were coinoculated with a commercial yoghurt starter. The antibacterial activity of fermented milk produced by L. plantarum isolates IMAU80106, IMAU10996, IMAU10216, IMAU70095, IMAU70023, IMAU30162, and IMAU10256 (but not IMAU30043 and IMAU50045) was greater in conjunction with a yoghurt starter compared to when the yoghurt starter was inoculated alone, as illustrated by the larger inhibition zones (Table 1).

A desirable increase in antibacterial activity was generally observed when L. plantarum was allowed to ferment together with a yoghurt starter compared to using the yoghurt starter alone (only showing a slight reduction in activity against $E$. coli and Shigella flexneri), particularly against the indicator pathogens, Salmonella 
Table 1 Antibacterial activity and persistence of this activity following protease treatment of milk fermented by a commercial yoghurt starter alone or in conjunction with selected isolates of L. plantarum (IMAU isolates)

\begin{tabular}{|c|c|c|c|c|c|}
\hline Fermentation isolates ${ }^{*}$ & $\begin{array}{l}\text { E. coli } \\
\text { O157:H7 }\end{array}$ & $\begin{array}{l}\text { Salmonella } \\
\text { typhimurium }\end{array}$ & $\begin{array}{l}\text { Shigella } \\
\text { flexneri }\end{array}$ & $\begin{array}{l}\text { Staphylococcus } \\
\text { aureus }\end{array}$ & L.monocytogenes \\
\hline $\begin{array}{l}\text { Commercial yoghurt } \\
\text { starter only (control) }\end{array}$ & $9.85 \pm 0.62^{\mathrm{bB}}$ & - & $9.15 \pm 0.92^{\mathrm{bB}}$ & - & - \\
\hline $\begin{array}{l}\text { Protease treatment only } \\
\quad(\text { control })^{\#}\end{array}$ & $18.93 \pm 0.22^{\mathrm{a}}$ & $17.59 \pm 0.19$ & $16.54 \pm 0.39^{\mathrm{a}}$ & $13.39 \pm 1.44$ & $20.30 \pm 0.38$ \\
\hline IMAU80106 & $15.49 \pm 1.59^{\mathrm{aA}}$ & $11.44 \pm 0.67$ & $12.65 \pm 0.83^{\mathrm{A}}$ & $11.53 \pm 0.84$ & $17.99 \pm 0.87$ \\
\hline Protease treatment & $10.66 \pm 0.49^{b}$ & - & - & - & - \\
\hline IMAU10996 & $17.17 \pm 1.57^{\mathrm{aA}}$ & $15.90 \pm 2.11$ & $15.38 \pm 2.10^{\mathrm{A}}$ & $12.62 \pm 0.94$ & $16.09 \pm 0.98$ \\
\hline Protease treatment & $9.70 \pm 0.00^{\mathrm{b}}$ & - & - & - & - \\
\hline IMAU10216 & $18.00 \pm 1.69^{\mathrm{aA}}$ & $15.22 \pm 0.80$ & $12.31 \pm 1.39^{\mathrm{A}}$ & $12.72 \pm 1.09^{\mathrm{a}}$ & $19.46 \pm 1.40$ \\
\hline Protease treatment & $13.46 \pm 0.77^{\mathrm{b}}$ & $16.40 \pm 0.30$ & $13.74 \pm 0.76$ & $9.83 \pm 0.43^{b}$ & $17.39 \pm 0.87$ \\
\hline IMAU70095 & $16.16 \pm 0.57^{\mathrm{A}}$ & $10.99 \pm 0.48$ & $14.55 \pm 0.91^{\mathrm{bA}}$ & $13.21 \pm 0.89$ & $21.99 \pm 1.44$ \\
\hline Protease treatment & $16.73 \pm 0.72$ & - & - & - & - \\
\hline IMAU70023 & $16.03 \pm 0.59^{\mathrm{aA}}$ & $12.69 \pm 1.23^{\mathrm{b}}$ & $12.60 \pm 1.28^{\mathrm{bA}}$ & $13.30 \pm 0.68^{\mathrm{a}}$ & $19.23 \pm 0.22^{\mathrm{a}}$ \\
\hline Protease treatment & $17.34 \pm 0.50^{\mathrm{b}}$ & $16.04 \pm 0.15^{\mathrm{a}}$ & $16.25 \pm 0.27^{\mathrm{a}}$ & $11.41 \pm 0.18^{\mathrm{b}}$ & $16.62 \pm 0.85^{\mathrm{b}}$ \\
\hline IMAU30043 & $9.60 \pm 0.78^{\mathrm{bB}}$ & - & $8.89 \pm 0.67^{\mathrm{B}}$ & $8.18 \pm 0.20$ & $11.38 \pm 0.43$ \\
\hline Protease treatment & - & $13.83 \pm 1.93$ & - & - & - \\
\hline IMAU50045 & $8.30 \pm 0.31^{\mathrm{bC}}$ & - & $8.32 \pm 0.24^{\mathrm{bB}}$ & - & $9.71 \pm 0.70^{\mathrm{b}}$ \\
\hline Protease treatment & $10.96 \pm 0.16^{\mathrm{a}}$ & $13.54 \pm 0.00$ & $13.24 \pm 0.12^{\mathrm{a}}$ & - & $12.37 \pm 0.42^{\mathrm{a}}$ \\
\hline IMAU30162 & $12.64 \pm 0.35^{\mathrm{bA}}$ & $13.87 \pm 1.05^{\mathrm{b}}$ & $15.55 \pm 0.78^{\mathrm{bA}}$ & $12.41 \pm 0.56$ & $17.11 \pm 0.74^{\mathrm{b}}$ \\
\hline Protease treatment & $18.43 \pm 0.13^{\mathrm{a}}$ & $21.26 \pm 0.98^{\mathrm{a}}$ & $21.17 \pm 0.27^{\mathrm{a}}$ & $13.16 \pm 0.98$ & $19.04 \pm 0.70^{\mathrm{a}}$ \\
\hline IMAU10256 & $14.06 \pm 0.62^{\mathrm{bA}}$ & $12.46 \pm 0.32^{\mathrm{b}}$ & $13.73 \pm 0.99^{\mathrm{bA}}$ & $9.24 \pm 0.85^{\mathrm{b}}$ & $15.38 \pm 0.91^{\mathrm{b}}$ \\
\hline Protease treatment & $15.56 \pm 0.52^{\mathrm{a}}$ & $18.09 \pm 0.58^{\mathrm{a}}$ & $16.14 \pm 0.03^{\mathrm{a}}$ & - & $17.06 \pm 0.02^{\mathrm{a}}$ \\
\hline
\end{tabular}

Data are expressed as means of triplicate replications $(\mathrm{mm}) \pm$ standard deviation. '-' means no visible inhibition zone. Numbers followed by different small superscript letters are significantly different from each other with respect to antibacterial activity of the resulting yoghurt in the absence of protease treatment $(p<0.05)$. Numbers followed by different capital superscript letters are significantly different from each other with respect to antibacterial activity of the resulting yoghurt following fermentation by a yoghurt starter alone or in combination with an IMAU isolate $(p<0.05)$

${ }^{*}$ Milk was fermented with either yoghurt starter only (as control) or yoghurt starter with an IMAU L. plantarum isolate

\# Each fermented milk was treated with protease (pepsin and trypsin) and tested for its antibacterial activity after treatment

typhimurium, Staphylococcus aureus, and L. monocytogenes. Although the exact mechanism for this remains undetermined in the current study, it does correlate with the fact that fermented milk produced by a combination of L. plantarum and a yoghurt starter had a significantly lower $\mathrm{pH}$ than milk fermented by the yoghurt starter alone (Table 2), presumably due to a higher concentration of lactic acid. The best characterized bacteriocin, nisin, is known to be more soluble and active at a lower $\mathrm{pH}$ range, and the combined use of nisin and lactic acid increased inhibition of Gram-negative bacteria compared with when either was used alone, which supports this hypothesis (Cleveland et al. 2001). Furthermore, it is known that the effectiveness of antimicrobial materials 
can be enhanced by other chemical substances and natural antimicrobials (Gálvez et al. 2007), which may have been produced by the cometabolism of the multiple coinoculated isolates. The exact mechanisms remain to be further elucidated.

3.3 Persistence of antibacterial activity in milk fermented by L. plantarum coinoculated with a commercial yoghurt starter, following challenge with proteases

Antibacterial activity against all five indicator pathogens was significantly greater in fermented milk produced by the control yoghurt starter alone after protease treatment, than without protease treatment, which was unexpected (Table 1). The effect of protease treatment on antibacterial activity of fermented milk produced by a combination of $L$. plantarum isolates and the yoghurt starter was highly variable compared with when no protease treatment was applied; for some L. plantarum isolates inoculated with the yoghurt starter protease treatment, it increased antibacterial activity, and for others, it decreased antibacterial activity (Table 1).

Pepsin and trypsin are proteases that are present in the stomach and the small intestine, respectively, and they aid digestion of proteins and peptides. Pepsin can damage leucine residues and $\mathrm{C}$-terminal aromatic amino acids, while trypsin preferentially attacks positively charged C-terminal amino acids such as arginine and lysine (Neurath 1957). Persistence of antimicrobial compounds in the presence of these enzymes is essential if they are to maintain their function in vivo. Fermented milks produced by a mixture of $L$. plantarum isolates IMAU50045, IMAU30162, and IMAU10256 with the commercial yoghurt starter displayed significantly stronger antibacterial activity against E. coli, Salmonella typhimurium, Shigella flexneri, and L. monocytogenes, but not Staphylococcus aureus after protease treatment compared with when there was no protease treatment. In contrast, the antibacterial activity of fermented milk produced by L. plantarum isolates IMAU70095, IMAU80106,

Table 2 Physical, chemical, and sensory properties of the nine selected isolates of L. plantarum

\begin{tabular}{|c|c|c|c|c|c|}
\hline Isolates & $\mathrm{pH}$ & $\begin{array}{l}\text { Viscosity } \\
\text { (cp) }\end{array}$ & $\begin{array}{l}\text { Titratable } \\
\text { acidity }\left({ }^{\circ} \mathrm{T}\right)\end{array}$ & $\begin{array}{l}\text { Free amino } \\
\text { nitrogen } \\
\left(\mathrm{mmol} . \mathrm{L}^{-1}\right)\end{array}$ & $\begin{array}{l}\text { Sensory } \\
\text { evaluation }\end{array}$ \\
\hline Yoghurt starter & $4.49 \pm 0.05^{\mathrm{a}}$ & $810 \pm 139.51^{b}$ & $68.21 \pm 1.40^{\mathrm{c}}$ & $2.58 \pm 0.11^{\mathrm{bc}}$ & $6.7 \pm 0.94^{\mathrm{a}}$ \\
\hline IMAU80106 & $4.29 \pm 0.01^{\mathrm{cd}}$ & $854 \pm 94.53^{\mathrm{b}}$ & $84.94 \pm 3.63^{\mathrm{ab}}$ & $2.32 \pm 0.48^{\mathrm{bc}}$ & $6.6 \pm 1.09^{\mathrm{a}}$ \\
\hline IMAU10996 & $4.29 \pm 0.01^{\mathrm{cd}}$ & $772 \pm 66.51^{b}$ & $81.67 \pm 1.44^{\mathrm{b}}$ & $2.46 \pm 0.46^{b c}$ & $7.0 \pm 1.11^{\mathrm{a}}$ \\
\hline IMAU10216 & $4.38 \pm 0.00^{\mathrm{b}}$ & $1060 \pm 200.16^{\mathrm{a}}$ & $83.52 \pm 4.59^{\mathrm{b}}$ & $2.80 \pm 0.07^{b c}$ & $6.6 \pm 1.03^{\mathrm{a}}$ \\
\hline IMAU70095 & $4.30 \pm 0.00^{\mathrm{cd}}$ & $870 \pm 40.10^{\mathrm{b}}$ & $83.46 \pm 1.06^{\mathrm{b}}$ & $2.90 \pm 0.44^{\mathrm{bc}}$ & $6.5 \pm 1.43^{\mathrm{a}}$ \\
\hline IMAU70023 & $4.26 \pm 0.00^{\mathrm{d}}$ & $888 \pm 77.00^{\mathrm{ab}}$ & $89.45 \pm 1.83^{\mathrm{ab}}$ & $3.22 \pm 0.13^{\mathrm{ab}}$ & $6.7 \pm 0.93^{\mathrm{a}}$ \\
\hline IMAU30043 & $4.28 \pm 0.00^{\mathrm{cd}}$ & $828 \pm 9.80^{b}$ & $81.11 \pm 0.60^{\mathrm{b}}$ & $2.78 \pm 0.59^{b c}$ & $6.6 \pm 0.96^{\mathrm{a}}$ \\
\hline IMAU50045 & $4.32 \pm 0.00^{\mathrm{c}}$ & $948 \pm 64.06^{\mathrm{ab}}$ & $80.06 \pm 1.51^{\mathrm{b}}$ & $3.85 \pm 1.01^{\mathrm{a}}$ & $6.4 \pm 0.87^{\mathrm{a}}$ \\
\hline IMAU30162 & $4.30 \pm 0.00^{\mathrm{cd}}$ & $852 \pm 77.77^{\mathrm{b}}$ & $95.37 \pm 17.38^{\mathrm{a}}$ & $2.00 \pm 0.71^{\mathrm{c}}$ & $6.3 \pm 0.87^{\mathrm{a}}$ \\
\hline IMAU10256 & $4.28 \pm 0.00^{\mathrm{cd}}$ & $864 \pm 51.65^{\mathrm{b}}$ & $78.77 \pm 2.89^{b}$ & $2.28 \pm 0.08^{b c}$ & $7.1 \pm 0.74^{\mathrm{a}}$ \\
\hline
\end{tabular}

Data are expressed as means of triplicate replications \pm standard deviation. Numbers followed by different small superscript letters are significantly different to each other within the same column $(p<0.05)$

* The sensory evaluation score was on a scale of 1 (obnoxious) to 9 (highly desirable) 
IMAU10996, and IMAU30043 in conjunction with the yoghurt starter was significantly reduced or completely lost after sequential pepsin and trypsin treatment, suggesting that the antibacterial compounds produced by these isolates during milk fermentation were proteins or peptides in nature and susceptible to digestion by these enzymes. Some L. plantarum isolates are known to exert their antibacterial activity via the production of bacteriocins (Hernández et al. 2005), and it is likely that the antibacterial activity that we observed in isolates IMAU70095, IMAU80106, IMAU10996, and IMAU30043 is based on a similar mechanism. Taking into consideration both tolerance to protease and persistence of antibacterial activity, we predict that isolate IMAU10216 is superior to all the other isolates that we evaluated in this study.

3.4 Physical, chemical, and sensory properties of milk fermented with selected L. plantarum isolates coinoculated with a commercial yoghurt starter

If isolates of L. plantarum are to be used effectively for their antibacterial properties in the production of fermented milk products, it is important that their presence does not negatively affect the desirable physical and chemical attributes of the final product. During fermentation, hydrolysis of the milk proteins occurs, the $\mathrm{pH}$ drops, the viscosity increases, and bacterial metabolites are produced that all contribute to the taste and, potentially, the health-promoting properties of yoghurt.

Adding L. plantarum as a probiotic in yoghurt production could not only provide beneficial health effects, but, because some physical and chemical attributes of the yoghurt are changed, also influence the sensory characteristics and acceptability of the final product to consumers. However, our results from the sensory evaluation show that, although presence of all the isolates reduced the $\mathrm{pH}$ and increased TA significantly, palatability of the yoghurt produced by each of the nine selected L. plantarum isolates when coinoculated with a commercial yoghurt starter was not significantly different to the control where the yoghurt starter was used alone (Table 2). Our results are similar to those of Hekmat and Reid (2006) who found that yoghurts containing the probiotics Lactobacillus reuteri RC-14 and Lactobacillus rhamnosus GR-1 were comparable in appearance, flavor, texture, and overall quality to the standard yoghurt without the probiotics.

\subsection{Tolerance to simulated gastrointestinal juices}

An ideal probiotic should be able to survive and multiply in the digestive tract if it is to provide in situ benefits to the consumer. For this reason, we evaluated the tolerance of the selected L. plantarum isolates in simulated gastrointestinal juices. Four of the selected L. plantarum isolates (IMAU10216, IMAU70095, IMAU70023, and IMAU50045) displayed high tolerance to sequential treatment with gastric and intestinal juices, with over $90 \%$ of cells surviving (Table 3). Isolates IMAU80106, IMAU30162, and IMAU10256 had moderate tolerance with a survival rate ranging from $76.5 \pm 1.18$ to $88.30 \pm 0.75 \%$, while IMAU30043 had a survival rate of $68.80 \pm 0.49$ (Table 3 ). Isolate IMAU30162 had very low tolerance with a survival rate of $<90 \%$ after the sequential treatments with simulated gastrointestinal juices. Thus, it is anticipated that IMAU10216 and IMAU70095 


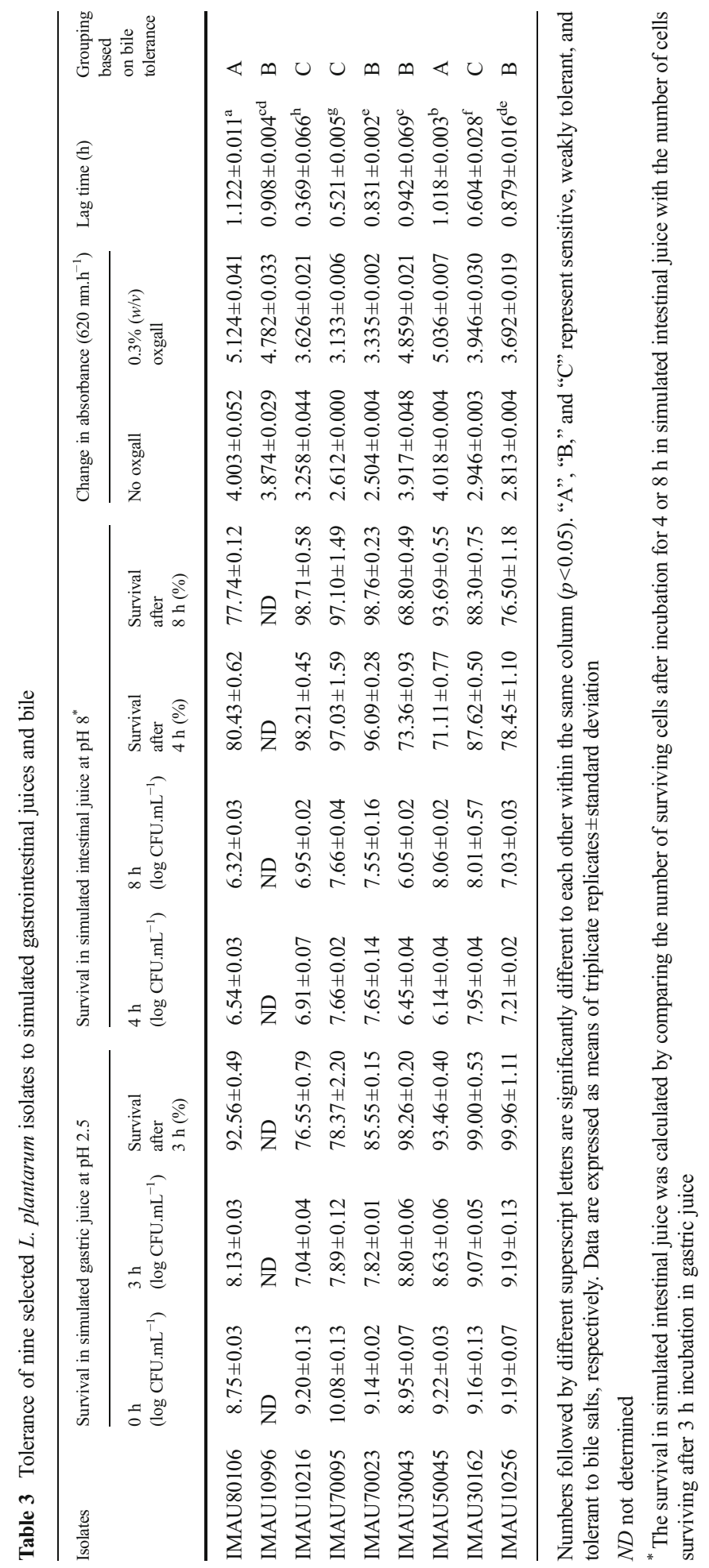


have a greater capacity to survive gastrointestinal transit. Anderson et al. (2010) found similar results for L. plantarum DSM 2648 which had good tolerance to gastrointestinal conditions in vitro with no loss of cell viability when incubated at $\mathrm{pH} 4.0$ and $0.5 \%$ bile for $4 \mathrm{~h}$.

\subsection{Bile tolerance}

We evaluated the tolerance of selected $L$. plantarum isolates to bile, as this is another crucial factor affecting the survival of probiotics in the digestive tract; bile salts in the small intestine damage cell membranes (De Vries et al. 2006). Only IMAU10216, IMAUI70095, and IMAU30162 were bile-tolerant, whereas the other isolates tested were either bile-sensitive or of low bile tolerance according to the classification of Gilliland et al. (1984). Takeda et al. (2011) found similar results with $L$. plantarum 05AM23 and 06TCa8 which showed superior bile tolerance under the conditions of $0.2 \%(w / v)$ oxgall than the other eight isolates of LAB evaluated.

\section{Conclusion}

Our study provides a preliminarily assessment of the antibacterial activity of 347 L. plantarum isolates against five common food-borne pathogens. Nine isolates had broad-spectrum antibacterial activity and were selected for further characterization. Subsequently, seven out of nine isolates increased antibacterial activity in the resulting yoghurt when they were fermented in combination with a yoghurt starter compared with the yoghurt starter alone. Yoghurt produced by three isolates retained or increased antibacterial activity even after protease treatment. The addition of $L$. plantarum had no significant effect on the palatability of the resulting yoghurt in sensory evaluations. Together, these results revealed that isolate IMAU10216 was the superior isolate over the others, particularly as it also exhibited high in vitro gastrointestinal tract tolerance. To conclude, this study has identified a novel bioactive antibacterial isolate of L. plantarum that has the potential to be suitable for use as a probiotic in the production of fermented milk products; further in vivo studies are now necessary.

Acknowledgments This research was supported by the National Key Technology Research and Development Program (Grant No. 2013BAD18B01), the Special Fund for Agro-scientific Research in the Public Interest (Grant No. 201303085), International S \&T Cooperation Program of China (ISTCP, 2014DFR31150), the China Agriculture Research System (Grant No. CARS-37), and the Program for Young Talents of Science and Technology in Universities of Inner Mongolia Autonomous Region (Grant No. NJYT-13-B11).

Conflict of interest There is no conflict of interest concerning this manuscript.

Ethical approval All procedures performed in studies involving human participants were in accordance with the ethical standards of the institutional and/or national research committee and with the Helsinki Declaration of 1964 and its later amendments or comparable ethical standards.

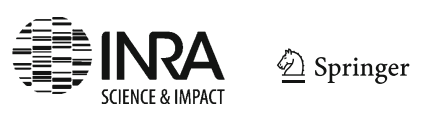




\section{References}

Anderson RC, Cookson AL, McNabb AL, Kelly WJ, Roy NC (2010) Lactobacillus plantarum DSM 2648 is a potential probiotic that enhances intestinal barrier function. FEMS Microbiol Lett 309:184-192. doi:10. 1111/j.1574-6968.2010.02038.x

Church FC, Swaisgood HE, Porter DH, Catignani GL (1983) Spectrophotometric assay using ophthaldialdehyde for determination of proteolysis in milk and isolated milk proteins. J Dairy Sci 66: 1219-1227. doi:10.3168/jds.S0022-0302(83)81926-2

Cleveland J, Montville TJ, Nes IF, Chikindas ML (2001) Bacteriocins: safe, natural antimicrobials for food preservation. Int J Food Microbiol 71:1-20. doi:10.1016/S0168-1605(01)00560-8

De Vries MC, Vaughan EE, Kleerebezem M, de Vos WM (2006) Lactobacillus plantarum-survival, functional and potential probiotic properties in the human intestinal tract. Int Dairy J 16(9):1018-1028. doi:10.1016/j.idairyj.2005.09.003

Gálvez A, Abriouel H, López RL, Omar NB (2007) Bacteriocin-based strategies for food biopreservation. Int J Food Microbiol 120:51-70. doi:10.1016/j.ijfoodmicro.2007.06.001

Gilliland SE, Staley TE, Bush LJ (1984) Importance of bile tolerance of Lactobacillus acidophilus used as a dietary adjunct. J Dairy Sci 67:3045-3051. doi:10.3168/jds.S0022-0302(84)81670-7

Hekmat S, Reid G (2006) Sensory properties of probiotic yoghurt is comparable to standard yoghurt. Nutr Res 26:163-166. doi:10.1016/j.nutres.2006.04.004

Hernández D, Cardell E, Zárate V (2005) Antimicrobial activity of lactic acid bacteria isolated from Tenerife cheese: initial characterization of plantaricin TF711, a bacteriocin-like substance produced by Lactobacillus plantarum TF711. J Appl Microbiol 99:77-84. doi:10.1111/j.1365-2672.2005.02576.x

Hussain M, Dawson C (2013) Economic impact of food safety outbreaks on food businesses. Foods 2:585589. doi:10.3390/foods2040585

Kaktcham PM, Zambou NF, Tchouanguep FM, El-Soda M, Choudhary MI (2012) Antimicrobial and safety properties of Lactobacilli isolated from two Cameroonian traditional fermented foods. Sci Pharm 80:189203. doi:10.3797/scipharm.1107-12

National Standards of the People's Republic of China (1996) Method for analysis of hygienic standard of milk and milk products. Bulletin 5009. 46. CNS, Beijing, China

Neurath H (1957) Some considerations of the multiple specificity of proteolytic enzymes. Ann NY Acad Sci 68:11-24. doi:10.1111/j.1749-6632.1957.tb42608.x

Nguyen TDT, Kang JH, Lee MS (2007) Characterization of Lactobacillus plantarum PH04, a potential probiotic bacterium with cholesterol-lowering effects. Int J Food Microbiol 113:358-361. doi:10.1016/j. ijfoodmicro.2006.08.015

Obi TE, Henshaw FO, Atanda OO (2010) Quality evaluation of plain-stirred probiotic yoghurt produced from skim and whole milk powder during refrigerated storage. Electron J Environ Agric Food Chem 9:12031213

Smaoui S, Elleuch L, Bejar W, Karray-Rebai I, Ayadi I, Jaouadi B, Mathieu F, Chouayekh H, Bejar S, Mellouli L (2010) Inhibition of fungi and Gram-negative bacteria by bacteriocin bacTN635 produced by Lactobacillus plantarum sp. TN635. Appl Biochem Biotechnol 162:1132-1146. doi:10.1007/s12010009-8821-7

Takeda S, Yamasaki K, Takeshita M, Kikuchi Y, Tsend-Ayush C, Dashnyam B, Ahhmed AM, Kawahara S, Muguruma M (2011) The investigation of probiotic potential of lactic acid bacteria isolated from traditional Mongolian dairy products. Anim Sci J 82:571-579. doi:10.1111/j.1740-0929.2011.00874.x

Usman, Hosono A (1999) Bile tolerance, taurocholate deconjugation, and binding of cholesterol by Lactobacillus gasseri strains. J Dairy Sci 82:243-248. doi:10.3168/jds.S0022-0302(99)75229-X

Vinderola CG, Costa GA, Regenhardt S, Reinheimer JA (2002) Influence of compounds associated with fermented dairy products on the growth of lactic acid starter and probiotic bacteria. Int Dairy J 12:579589. doi:10.1016/S0958-6946(02)00046-8

Walker DK, Gilliland SE (1993) Relationship among bile tolerance, bile salt deconjugation, and assimilation of cholesterol by Lactobacillus acidophilus. J Dairy Sci 76:956-961. doi:10.3168/jds.S0022-0302(93) 77422-6

Zhang HP, Chen YF, Liu WJ, Sun ZH, Bao QH, Zhang WY (2012) Biological diversity of lactic acid bacteria in natural fermented dairy products, 1 st edn. Science Press, Beijing 